\title{
The Trigger Point Therapy Workbook: Your Self-Treatment Guide for Pain Relief. 3rd ed.
}

By Clair Davies and Amber Davies. 376 pp. Oakland, CA: New Harbinger Publications; 2013. \$16.84.

ISBN: 978-1-60882-494-6 (Paperback)

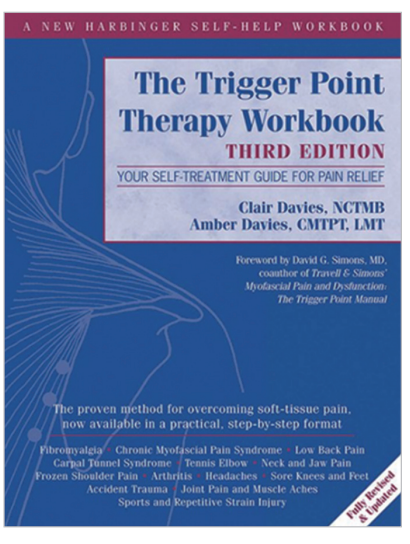

Trigger point therapy is a concept that is vaguely understood by the medical community outside of those specializing in pain treatment. It is a subject not enthusiastically discussed or taught during Western style medical school or training. However, it has been widely practiced as a form of treatment throughout Asia for hundreds of years. Recently, there has been an increase in the number of publications on trigger point therapy for urological pelvic pain.

Although this book is intended for the laymen, it can provide a quick and practical overview of the trigger point concept in an easy to understand language and layout to the medical community interested in the subject. After discussing the general concept of trigger point, the authors provide a practical way to detect and relieve trigger point pain from each section of the body, starting from the head to the foot. One chapter covers the chest, abdominal and genital pain. What is interesting is that the authors describe the culprit muscles and treatment methods for those hard to treat symptoms such as penis, scrotal, testicular, and ejaculatory pain. This book is recommended for anyone who wants to start understanding the concept and application of trigger points.

Jang Hwan Kim Department of Urology, Yonsei University

College of Medicine E-mail: jkim@yuhs.ac

This is an Open Access article distributed under the terms of the Creative Commons Attribution Non-Commercial License (http://creativecommons.org/licenses/by-nc/3.0/) which permits unrestricted non-commercial use, distribution, and reproduction in any medium, provided the original work is properly cited. 